\title{
INDICES OF FATTY ACIDS SPECTRUM OF LIPIDS IN THE BLOOD SERUM OF STERLET OF DIFFERENT AGE
}

\author{
Roza Suleimanova \\ Department of biochemistry and physiology of animals named after Academician M. F. Gulyi \\ National University of Life and Environmental Sciences of Ukraine \\ 15 Heroiv Oborony str., Kyiv, Ukraine, 03041 \\ 1992_s_roza@ukr.net \\ Dmytro Melnychuk \\ Advisor to the Presidium of the National Academy of Sciences of Ukraine \\ 54 Volodymyrska str., Kyiv, Ukraine, 01601 \\ Liliia Kalachniuk \\ Department of biochemistry and physiology of animals named after Academician M. F. Gulyi \\ National University of Life and Environmental Sciences of Ukraine \\ 15 Heroiv Oborony str., Kyiv, Ukraine, 03041 \\ kalachnyuk_liliya@nubip.edu.ua
}

\begin{abstract}
As the only sturgeon living in freshwater, sterlet is important for breeding in industrial fish farms, where lately cases of early mortality of this species have been detected. Hence, in order to preserve the species, it is important to study the parameters of fatty acid (FA) composition of lipid fractions of the blood serum of sterlet.

Here we present changes of fatty acid composition in different lipid fractions of the blood serum of sterlets of different age (namely two-, three- and nine-year-old) with the masses $0.3-0.4,0.5-0.6$ and 5-6 kg for the age-groups of fish, respectively. Fatty acid (FA) composition was determined using gas-chromatography on HRGC 5300 (Italy) in Palladin Institute of Biochemistry of the National Academy of Sciences of Ukraine (NASU). Fatty acid composition of starlet blood serum is presented by saturated and unsaturated high-molecular weight carboxylic acids, mostly palmic, stearic, oleic and linoleic. In the phospholipids fraction, there was a moderate increase in saturated and monounsaturated fatty acids and a slight decrease in polyunsaturated fatty acids depending on the age of fish. As for free fatty acids, there was a drop in the saturated ones depending on the starlet age. Among the free fatty acids of sterlet blood serum, we identified 28 acids, of them $39 \%, 35 \%$ and $30 \%$ were saturated in 2-, 3-year-old and mature fish, respectively. Monounsaturated FA content was $14 \%, 23 \%$ and $23 \%$ in 2-, 3-year-old and adult sterlet fish, and polyunsaturated FA content $-46 \%, 41 \%$ and $36 \%$, respectively. The data can be used for the theoretical verification of correcting supplementary feed and premixes.
\end{abstract}

Keywords: sterlet, blood, lipids, saturated fatty acids, monounsaturated fatty acids, polyunsaturated fatty acids.

DOI: $10.21303 / 2504-5695.2018 .00578$

(C) Roza Suleimanova, Dmytro Melnychuk, Liliia Kalachniuk

\section{Introduction}

Fatty acids composition of lipids in organs and tissues of fish depends on several factors: species, age, conditions of breeding, feeding type [1]. They take part in metabolic processes, colon absorption of vitamins and minerals and accumulation of energy. Some fatty acids are mostly used as the substrates for metabolism, others - as a source of synthesis of physiologically active compounds (prostaglandin, leukotriene, thromboxane) that are important precursors in the blood circulation [2]. Along with this, fatty acids in the composition of lipid compounds are structural elements of the membrane which simultaneously act as the main substrates of the lipid peroxidation processes.

Hence, qualitative and quantitative changes in the fatty acid composition can be a specific criterion for assessing the intensity of the prooxidant-antioxidant balance in the tissues of the organism [3]. Available in the literature data [4] indicate difference in the content of lipids and their fatty acid composition in the tissues of pond fish due to the species and age diversities. Peculiarities of the fatty acid composition of lipids, including various factions lipid in tissues of sterlet depending on age were studied less, therefrom deepening these investigations is topical. 


\section{Aim of research}

To study the parameters of the fatty acid (FA) composition of lipid fractions of the blood serum of starlet depending on age that are important for the theoretical justification and development of appropriate corrective feed additives and premixes.

\section{Materials and methods}

The object of the study was the blood of sterlets of different age groups: two-year-olds (with a mass of $0.3-0.4 \mathrm{~kg})$, three-year-olds $(0.5-0.6 \mathrm{~kg})$ and mature (nine-year-old, 5-6 kg). Blood samples were collected at the fish farm "Osetr" in Ukraiinka village of Obukhivskii district of Kyiv region during the spring period of 2016.

Extraction of blood serum lipids was carried out by the method of J. Folch et al. [5]. The lipid fractions were separated by thin layer chromatography using a hexane/diethyl ether/acetic acid solvent system (85:15:1). The fatty acid methyl esters were prepared using the modified method of I. D. Carreau and I. P. Dubaco [6].

All interventions and slaughter of animals were carried out according to the national General Ethical Principles of Experiments on Animals [7] and the requirements of the European Convention on the Protection of Vertebrate Animals Used for Experimental and Other Scientific Purposes (Strasbourg, 1986).

Fatty acids were determined using gas-chromatography on HRGC 5300 (Italy) in Palladin Institute of Biochemistry of NASU. Glass column of $3.5 \mathrm{~m}$ of length was packed with Chromosorb W/HP and equilibrated with $10 \%$ Silar $5 \mathrm{CP}$ at a programmed temperature of $140-250{ }^{\circ} \mathrm{C}$ that has been increasing $2{ }^{\circ} \mathrm{C} / \mathrm{min}$. Identification of individual FA was performed using standards purchased from Sigma and Serva, the content was expressed as a percentage of the total mass of fatty acids.

Data is expressed as mean \pm SEM for at least 5 sterlets per age-group. Student's t-test was used for all analyses and values of $\mathrm{p} \leq 0.05$ were considered to indicate statistically significant difference. All calculations were performed using OriginLab, Microsoft Excel software for t-test analysis.

\section{Results}

The fatty acids composition of blood serum lipids in sterlet is represented by saturated and unsaturated high molecular weight carboxylic acids, the largest content of which belongs to palmitic and stearic, and oleic and linoleic acid, respectively. One of the main factors that influence the physical and chemical properties of the lipid bilayer of cellular membranes is the ratio of saturated/ unsaturated fatty acids. Numerical values of the ratio of saturated / unsaturated fatty acids are different in various lipid fractions in sterlets. They range from 0.47 to $0.77,0.44-0.76,0.34-0.84$ in $2-$, 3 -year-old and mature sterlets, respectively, conforming to the recommendations of the WHO and the FAO, according to which this ratio should be greater than 0.4 .

Thus, according to the results of research in phospholipids of the blood serum in sterlet, it was recorded a slight increase in the content of saturated and monounsaturated fatty acids, and a decrease of the level of polyunsaturated fatty acids with age (Fig. 1, a).

Figure 1 shows that in the blood serum phospholipids of sterlet, there was a high content of unsaturated fatty acids, which make up more than $50 \%$ of the total amount of fatty acids. In this case, the proportion of polyunsaturated fatty acids in the composition of phospholipids of the blood serum of sterlet is more than $30 \%$ of the total amount of fatty acids. Thus, the total proportion of polyunsaturated fatty acids was $36.4 \%, 34.8 \%$ and $33.5 \%$ in the blood serum phospholipids of sterlets of 2-, 3- and 9-year-old, respectively. When analyzing the content of polyunsaturated fatty acids in phospholipids of the blood serum of sterlet of different age (2-, 3- and 9-year old), attention is drawn to the high relative content of their composition of linoleic (18: 2) - 37.8\%, $40 \%$ and $43 \%$, arachidonic $-0.7 \%, 1.5 \%$ and $3.3 \%$ and docosahexaenoic acids $-0.1,0.15$, and $0.76 \%$ of the total amount of fatty acids.

In the fraction of triacylglycerols in the blood serum of sterlet, the growth of saturated fatty acids content was also found (Fig. 1, b). Regarding free fatty acids (Fig. 1, c), there was a decrease in saturated fatty acids with age. Monoenoic and polyenoic (except dienoic) fatty acids in this frac- 
tion increased significantly with age. At the same time, in the cholesterides (Fig. 1, $\boldsymbol{d}$ ), the content of saturated fatty acids decreased with age as well. Dienoic and polyenoic fatty acids also decreased and monoenoic ones increased.

According to the results of the study, there are significant changes in the composition of individual free fatty acids of blood plasma of different age groups (Fig. 2). As a part of the free fatty acids of lipids of the blood serum of sterlets, 28 fatty acids have been identified, of which 39 , 35 and $30 \%$ of the total mass of fatty acids are saturated fatty acids in 2-, 3-year-old and mature fish, respectively. Mono-unsaturated fatty acids make up 14, 23 and $23 \%$ in 2-, 3- and 9-year-old sterlets, respectively, and 46,41 and $36 \%$ of polyunsaturated fatty acids were in respective agegroups of fish (Fig. 1).

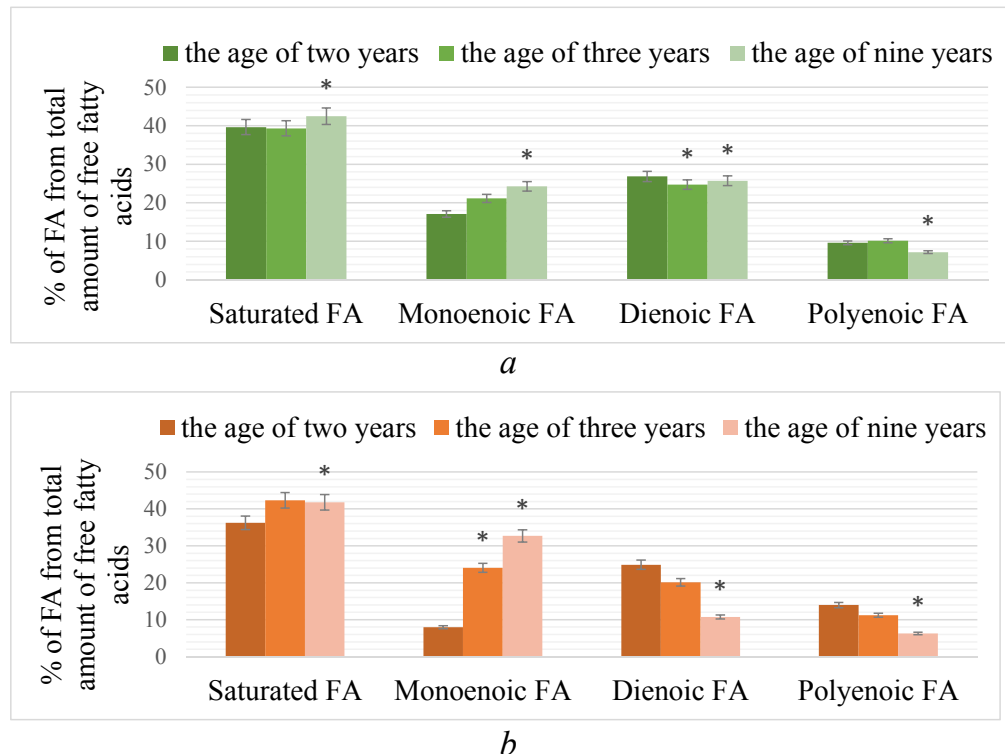

$b$
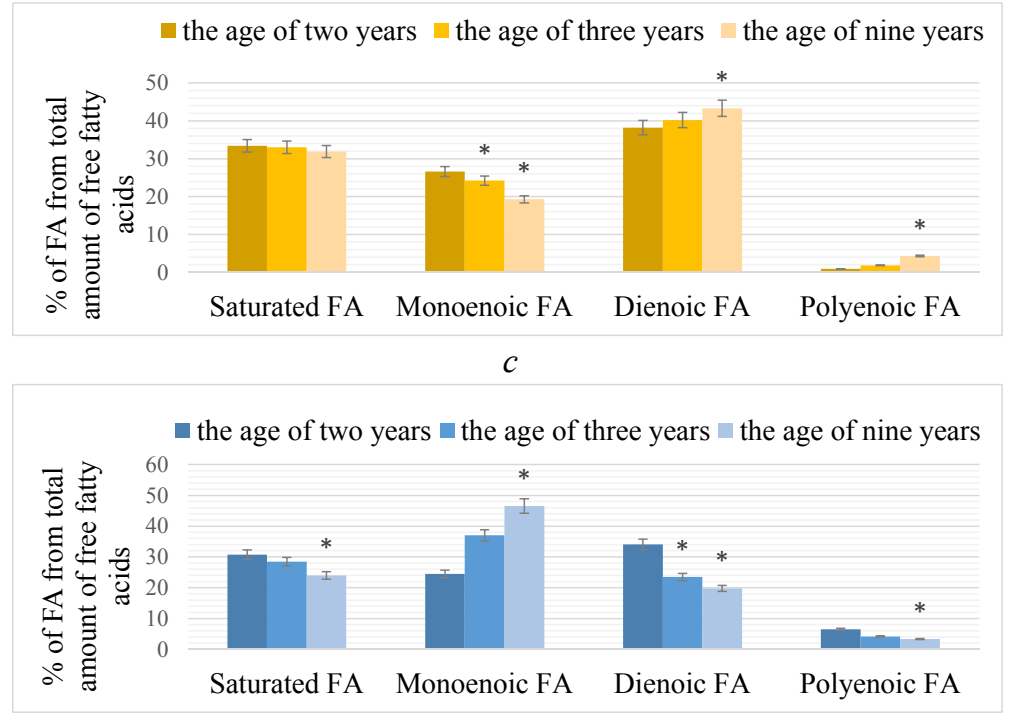

$d$

Fig. 1. The content of unsaturated fatty acids in different lipid fractions of blood plasma of sterlet of various age groups: $a$ - phospholipids; $b$ - triacylglycerols; $c$ - free fatty acids;

$d$ - cholesterol $(\mathrm{n}=5) ;{ }^{*}$ - Results were significant for $\mathrm{P} \leq 0.05$

Among the saturated, there were twelve fatty acids. Palmitic acid dominates, the content of which has become less for $9 \%$ in mature sterlets in comparison with 2-year-old fish (Fig. 2). The content of stearic acid is significant. Stearic acid unlike palmitic increased with fish age and it was 
$1.5,4$, and $5 \%$ in 2-, 3-year-old and mature sterlets. The part of all other acids is less than $1 \%$. Oleic acid has decreased almost in 1.5 times in mature sterlets compared to two-year-old ones (Fig. 2).

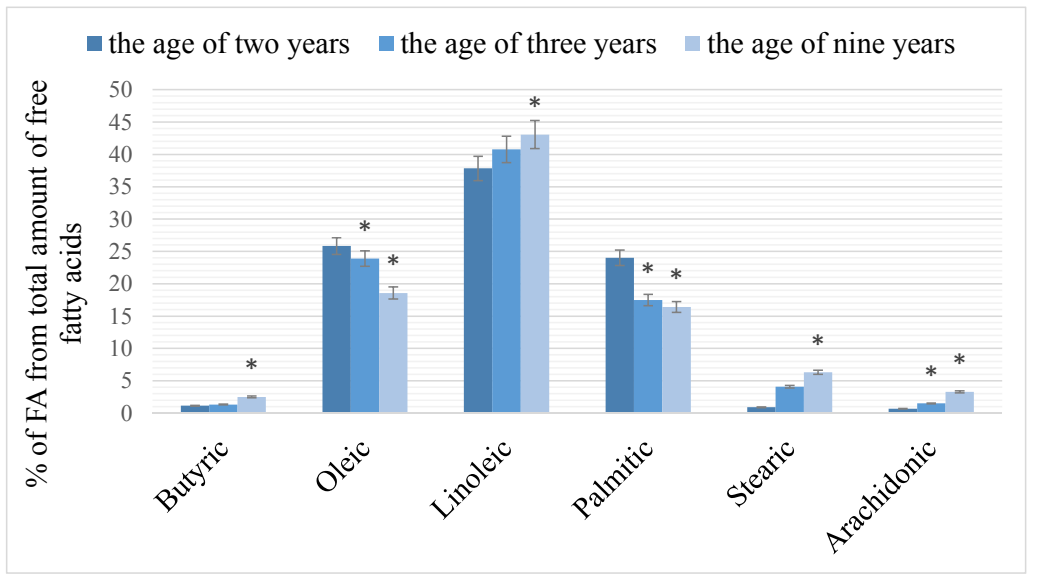

Fig. 2. The content of free fatty acids in the plasma of blood of various age groups, $n=5$; $*-\mathrm{P}<0.05$

\section{Discussion}

The study of the peculiarities of changes in the fatty acid composition of lipids, in particular in different lipid fractions, in the blood serum of sterlet (Acipenser ruthenus Linnaeus) depending on the age can be important for determining the etiology and pathogenesis of hepatosteatosis, which often occurs in conditions of artificial rearing of the specified species of fish in the warm waters of the power station.

Changes in the exchange of saturated and unsaturated fatty acids have a multifaceted adverse effect on a number of metabolic processes: the disruption of oxidative phosphorylation, inhibition of the system of mitochondrial enzymes, violation of the transport function of the membrane [6]. The latter are manifested by changes in lipid metabolism, atherogenic lipoproteins and triglycerides, glucose, and the activity of the endothelial and smooth muscle cells of the vascular wall.

Saturated fatty acids and monounsaturated omega- 9 oleic acid promote the synthesis of ATP in the mitochondrial chain of $\beta$-oxidation of fatty acids, providing $60-70 \%$ of the energy requirement of the myocardium. The deficiency of saturated fatty acids, in particular, palmitic acid, may cause a constraint on the transport and trophic supply of the vascular wall, which results in the development of arterial hypertension [9].

Increasing the content of highly unsaturated fatty acids in lipids of the cellular membranes determines their ability to stay in the liquid state at low temperatures and thereby ensure the effective functioning of the membranes [10].

In cold-blooded organisms, in particular, fish, the fluid-crystalline state of cellular membranes is mainly due to the high level of polyunsaturated fatty acids in the membranal phospholipids, which, in turn, provides transmembrane transport and the normal functioning of membrane-bound enzymes [11]. These results are consistent with the literature data on the high content of polyunsaturated fatty acids in the lipids of various species of fish [12].

One of the most important functions of stearic acid is the conservation of energy supplies [13]. Among the monounsaturated fatty acids, oleic acid has the highest content. Palmitic and oleic acids are involved in the construction of biological membranes. The presence of large quantities of oleic acid in the fatty depot ensures the stability of the deposited lipids to oxidize the moderate amount of antioxidants [14].

Polyunsaturated fatty acids are a part of a series of bio-regulators, which are formed from other lipids by enzymatic catalysis [15]. It was established that their content correlates with the course of free radical processes [16]. It is known that the content of polyunsaturated fatty acids in fish lipids is higher compared to mammals. As a result, the fish organism is more susceptible to the intensification of LPO processes and more dependent on antioxidant status [7]. 
Polyunsaturated fatty acids in the blood serum of sterlets are mainly represented by linoleic, eicosapentaenoic and docosahexaenoic acids. Linoleic and arachidonic acids have a key role in the processes of life of freshwater fish [10]. The content of the latter in the blood serum of investigated fish is rather low, but with age, it increases. The deficiency of linoleic acid in the freshwater fish diet leads to slowing growth and morphological changes in the skin [19]. At the same time, in tissues of fish, as well as in mammals, the synthesis of eicosatrienoic acid is compensatorily increased and this acid is used in the synthesis of tissue lipids [20].

\section{Conclusion}

For the first time, it was studied the fatty acid composition of the blood serum of sterlet of different age.

1. According to the experimental results of studies of phospholipids in the blood serum of sterlets, there was a significant increase in the content of saturated and monounsaturated fatty acids and a decrease of the level of polyunsaturated fatty acids depending on fish age.

2. 28 free fatty acids have been identified in the blood serum of sterlets, of which saturated fatty acids have $39 \%$ of the total mass of fatty acids in 2 -year-old sterlets, $35 \%$ - in 3 -year-old ones and $30 \%$ - in mature fish.

3. It was shown a decrease in free saturated fatty acids with age.

4. Mono-unsaturated fatty acids make up $14 \%$ in 2-year-old sterlets, $23 \%$ - in 3-year-old ones, $23 \%$ - in sexually mature fish, polyunsaturated fatty acids - $46 \%, 41 \%$ and $36 \%$, respectively.

All this can be used for the theoretical justification and development of appropriate corrective feed additives and premixes.

\section{Acknowledgement}

Authors gratefully acknowledge the supervisors and co-workers of the fishfarm "Osetr" in Ukrainka village of Obukhivskii district of Kyiv region for kindly providing biological material.

\section{References}

[1] Suleimanova, R. R., Hudz, E. A., Melnychuk, D. O., Kalachniuk, L. H. (2017). Age-related changes phospholipids of sterlet in liver and dorsal muscles. The Ukrainian Biochemical Journal, 89 (1), 71-75. doi: 10.15407/ubj89.01.071

[2] Jastroch, M., Giroud, S., Barrett, P., Geiser, F., Heldmaier, G., Herwig, A. (2016). Seasonal Control of Mammalian Energy Balance: Recent Advances in the Understanding of Daily Torpor and Hibernation. Journal of Neuroendocrinology, 28 (11). doi: 10.1111/jne.12437

[3] Yanovych, N. (2013). Fatty acids composition of carp (cyprinus carpio) skeletal muscles under influence of different copper and zinc concentration in water. Ribogospodars'ka Nauka Ukraïni, 2 (24), 70-75. doi: 10.15407/fsu2013.02.070

[4] Suleimanova, R. R., Hudz, I. A., Melnychuk, D. O., Kalachniuk, L. H. (2017). Age peculiarities of the content of phospholipids in the blood of sterlet. Reports of the National Academy of Sciences of Ukraine, 5, 98-101. doi: 10.15407/dopovidi2017.05.098

[5] Folch, J., Lees, M., Sloane Stanley, C. (1957). A simple method for the isolation and purification of total lipides from animal tissues. Ukrainian Biochemical Journal, 226 (1), 497-511.

[6] Carreau, J. P., Dubacq, J. P. (1978). Adaptation of a macro-scale method to the micro-scale for fatty acid methyl transesterification of biological lipid extracts. Journal of Chromatography A, 151 (3), 384-390. doi: 10.1016/s0021-9673(00)88356-9

[7] Reznikov, O. H. (2003). Zahalni etychni pryntsypy eksperymentiv na tvarynakh. Pershyi natsionalnyi konhres z bioetyky [General ethical principles of animal experimentation. First National Congress on Bioethics]. Endocrinol., 8 (1), 142-145.

[8] Tsvetkova, M. V., Khirmanov, V. N., Zybina, N. N. (2010). Significance of non-etherificated fatty acids in pathogenesis of cardiovascular diseases, Arterial'naya Gipertenziya, 6 (1), 93-103.

[9] Khuda, L. V., Marchenko, M. M., Khudyi, O. I. (2014). Zhyrnokyslotnyi sklad m'iaziv sterliadi, vyroshchenoi v umovakh rybovodnoi retsyrkuliatsiinoi systemy [Fatty acid composition of muscles of sterlet, grown in the conditions of a fish water recirculation system]. Ukrainian Biochemical Journal, 86, 263. 
[10] Govorin, A. V. (2010). Non-coronarogenic myocardial damages, Novosibirsk: Nauka, 230.

[11] Kuo, C. M., Hsieh, S. L. (2006). Comparisons of physiological and biochemical responses between milkfish (Chanos chanos) and grass carp (Ctenopharyngodon idella) to cold shock. Aquaculture, 251 (2-4), 525-536. doi: 10.1016/j.aquaculture.2005.05.044

[12] Lyavrin, B. Z., Kurant, V. Z., Khomenchuk, V. O., Grubinko, V. V. (2014). Species peculiarities of the lipid composition of some freshwater fish tissues of the Western Podillya. Reports of the National Academy of Sciences of Ukraine, 8, 123-127. doi: 10.15407/dopovidi2014.08.123

[13] Nelson, D. L., Cox, M. M. (2017). Lehninger Principles of Biochemistry. New York: W.H. Freeman, 1328 .

[14] Melnychuk, D. O., Melnychuk, S. D., Arnauta, O. V. (2004). Influence of carbon dioxide on the environment preservation of red blood cells in stored blood of animals. Scientific Bulletin of NAU, 75, $163-165$.

[15] Yli-Jama, P., Seljeflot, I., Meyer, H. E., Hjerkinn, E. M., Arnesen, H., Pedersen, J. I. (2002). Serum non-esterified very long-chain PUFA are associated with markers of endothelial dysfunction. Atherosclerosis, 164 (2), 275-281. doi: 10.1016/s0021-9150(02)00067-9

[16] Leeson, C. (2002). Relationship between circulating n-3 fatty acid concentrations and endothelial function in early adulthood. European Heart Journal, 23 (3), 216-222. doi: 10.1053/euhj.2001.2728

[17] Silkin, Y. A., Silkina, E. N., Zabelinskii, S. A. (2012). Peculiarities of the phospholipid and fatty acid composition of erythrocyte plasma membranes of the black sea fish. Journal of Evolutionary Biochemistry and Physiology, 48 (1), 43-51. doi: 10.1134/s0022093012010069

[18] Gritsyanak, I. I., Smolyaninov, K. B., Janovich, V. G. (2010). Obmin lipidiv u ryb [Exchange of lipids in fish]. Lviv: Triad plus.

[19] Li, G., Sinclair, A. J., Li, D. (2011). Comparison of Lipid Content and Fatty Acid Composition in the Edible Meat of Wild and Cultured Freshwater and Marine Fish and Shrimps from China. Journal of Agricultural and Food Chemistry, 59 (5), 1871-1881. doi: 10.1021/jf104154q

[20] Du, Z.-Y., Clouet, P., Zheng, W.-H., Degrace, P., Tian, L.-X., Liu, Y.-J. (2006). Biochemical hepatic alterations and body lipid composition in the herbivorous grass carp (Ctenopharyngodon idella) fed high-fat diets. British Journal of Nutrition, 95 (5), 905-915. doi: 10.1079/bjn20061733 